\title{
British government hedges bets on embryo research
}

\section{- Long-awaited white paper pulls punches - New licensing authority set up}

\section{London}

THE British government has taken the first tentative steps towards legislating on assisted fertilization and embryology with the publication last week of a longawaited white paper* (policy document) on the issues dealt with in the report of a committee chaired by Dame Mary Warnock, published three years ago (Nature 310, 266; 1984). The government has failed, however, to take a stand on embryo research - the white paper contains two alternative proposals, one banning research, the other permitting limited research on embryos up to 14 days old. Parliament will be given a free vote.

The white paper broadly follows the recommendations of the Warnock committee, with the central proposal being to establish a statutory licensing authority to regulate infertility treatment and, if it is permitted, embryo research. It does not follow Warnock's recommendation to legislate against non-commercial surrogacy. Licensing. A Statutory Licensing Authority (SLA) would license research or treatment involving human embryos created in vitro or procured from the uterus; treatment involving the use of donated gametes (for example, artificial insemination by donor) or donated embryos; the storage "in an arrested state of development" (currently by freezing) of human gametes or embryos for use later; and the use of diagnostic tests involving penetration by human sperm of an animal ovum. Licences would be renewable and granted for up to five years. It would be a criminal offence to undertake without a licence any of these activities.

The SLA's chairman and members (between 15 and 20 ) would be appointed, for a fixed, renewable term, by the Secretary of State for Social Services. The chairman and at least half the members would be lay people, and at least one-third doctors or scientists with relevant experience. The SLA would be funded partly by the state, but mostly by licence fees.

Embryo research. The draft clause prohibiting research reads: "It will be a criminal

\section{CLAMP ON FRANKENSTEIN

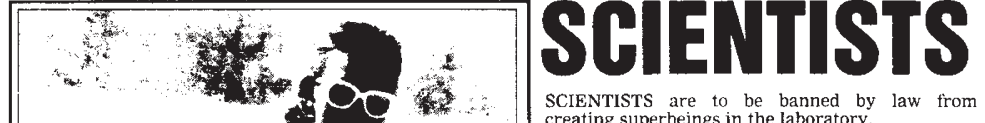 \\ SCIENTISTS are to be banned by law from}

offence to carry out any procedures on a human embryo other than those aimed at preparing the embryo for transfer to the uterus of a woman; or those carried out to ascertain the suitability of that embryo for the intended transfer". The clause permitting research begins: "Except as part of a project specifically licensed by the SLA, it will be a criminal offence ..." In either case, storing embryos is allowed.

If research is permitted, the government proposes to accept the Warnock recommendation that a licence would forbid the use of embryos beyond 14 days after mixing the sperm and egg or after the appearance of the primitive streak, whichever is the earlier. Research licences would be linked to a specific project and would expire after a maximum of two years. For the SLA to grant a licence, it would need to be satisfied that the research was aimed at advancing diagnostic or therapeutic techniques of fertility control, was scientifically valid and that no reasonable alternative was available. The consent of the donors of the embryo or the gametes would be required.

The government's sensitivity to public opinion is illustrated by its rejection of the recommendation that the SLA should be responsible for issuing guidance on research unlikely to be considered ethically acceptable in any circumstances, such as cloning or genetic engineering. The white paper proposes that "the legislation should prohibit all such activities, but with the power for Parliament itself ... to make exceptions

Control and storage. A licence from the SLA would be required to operate storage facilities for gametes or embryos whose control would be in accordance with the donor's wishes. The maximum storage time for embryos would be five years "or such lesser time as the SLA determines" and for gametes ten years. Transfer of gametes or embryos between facilities would require both parties to hold a licence, unless authorized by the SLA. The sale and purchase of human gametes and embryos would be controlled to avoid

The popular press in Britain promotes a less than flattering view of scientists; Today's response to last week's white paper.

\section{Voluntary authority sighs with relief}

\section{London}

THE body that at present monitors programmes of in vitro fertilization (IVF) and embryo research, the Voluntary Licensing Authority (VLA), has welcomed the white paper with relief. The VLA was set up in 1985 as a temporary measure. Its lack of statutory powers and the rapid evolution of techniques in the field has put its part-time membership and staff under increasing strain.

The VLA is presently considering requests from several IVF clinics to relax its guideline that relatives of infertile patients should not be allowed to donate gametes, on the principle that the anonymity of the donor is in the interests of the child.

Public interest in IVF has been heightened during the past few weeks, centring on the activities of the private Humana Hospital Wellington in London, which has Britain's largest IVF unit. The VLA withdrew its licence when the hospital refused to forbid the transfer of more than four eggs at a time. Since then the hospital has agreed to abide by the rules. The hospital also sacked from its ethics committee for breach of confidentiality a doctor who had supplied the VLA with details of the hospital's practices. Police are also investigating allegations that having transferred more than four eggs the unit selectively reduced the number of fetuses, possibly an offence of procuring an unlawful miscarriage.

Discussion of the ethical issues of IVF and embryo research will doubtless become entwined with the current public debate on abortion. A Liberal Member of Parliament, Mr David Alton, is seeking to change the time limit for abortion from the present 28 weeks to 18 .

Simon Hadlington

the risk of commercial exploitation.

Surrogacy. Most of the Warnock committee wanted legislation against private surrogacy arrangements. In 1985 the government made it an offence for a third party to take part in negotiations for a commercial surrogacy arrangement. The white paper says it would be innappropriate and not "necessarily in the child's best interests to make private, non-commercial surrogacy arrangements an offence.

All adults over the age of 18 would have the legal right to find out whether they were born following gamete or embryo donation, and the right of access to "certain non-identifying information". Where a child results from donated gametes or embryos, the carrying mother would legally be the child's mother. The donors would have no parental rights or duties.

Simon Hadlington

*Human Fertilisation and Embryology: A Framework for Legislation (Cmnd 259, HMSO, £3.30). 